\title{
Mycobacterium pyrenivorans sp. nov., a novel polycyclic-aromatic-hydrocarbon-degrading species
}

\author{
Kerstin Derz, ${ }^{1}$ Ulrich Klinner, ${ }^{2}$ Ingolf Schuphan, ${ }^{1}$ Erko Stackebrandt ${ }^{3}$ \\ and Reiner M. Kroppenstedt ${ }^{3}$ \\ 1,2Department of Ecology, Ecotoxicology and Ecochemistry ${ }^{1}$ and Unit of Applied Microbiology, \\ Department of Microbiology and Genetics², Aachen University, Worringerweg 1, D-52056 \\ Aachen, Germany \\ ${ }^{3}$ Deutsche Sammlung von Mikroorganismen und Zellkulturen $\mathrm{GmbH}$, Mascheroder Weg 1b, \\ D-38124 Braunschweig, Germany
}

\begin{abstract}
The taxonomic position of a polycyclic-aromatic-hydrocarbon-degrading bacterium, strain $17 \mathrm{~A}^{\top}$, isolated from contaminated soil was determined using a combination of phenotypic and genotypic properties. The isolate showed phenotypic properties that were diagnostic for species of the genus Mycobacterium. Comparative 16S rRNA gene sequence analysis assigned $17 \mathrm{~A}^{\top}$ to the $16 \mathrm{~S}$ rRNA gene subgroup that contains Mycobacterium aurum, Mycobacterium austroafricanum, Mycobacterium vaccae and Mycobacterium vanbaalenii, but it could clearly be distinguished from these species using a combination of physiological, chemotaxonomic markers and internal rRNA gene spacer analyses. The data showed that strain $17 A 3^{\top}(=D S M$ $44605^{\top}=$ NRRL B-24244 ${ }^{\top}$ ) merits recognition as the type strain of a novel species of the genus Mycobacterium. The name Mycobacterium pyrenivorans sp. nov. is proposed for the species because of its ability to use pyrene as a sole source of carbon and energy.
\end{abstract}

The Corynebacterineae, a suborder of the order Actinomycetales (Stackebrandt et al., 1997), is the taxon that harbours most xenobiotic degraders among Gram-positive bacteria. Namely, species of the genera Gordonia, Rhodococcus and Mycobacterium are well known for their capacity to degrade environmentally hazardous chemicals (Bell et al., 1998; Williumsen \& Karlson, 1997). In this paper, we describe a novel pyrene-degrading, rapidly growing isolate that represents a novel species of the genus Mycobacterium.

Strain $17 \mathrm{~A}^{\mathrm{T}}$ was isolated from an enrichment culture obtained from soil that was highly contaminated with polycyclic aromatic hydrocarbons (PAHs). The soil sample was collected on the site of a former coking plant at ÜbachPalenberg, Germany. An enrichment culture of indigenous bacteria was extracted from soil with $0 \cdot 2 \%$ tetrasodium pyrophosphate and was cultivated in mineral medium amended with phenanthrene, anthracene, pyrene, fluoranthene and benzo[a]pyrene (100 $\mathrm{mg} \mathrm{l}^{-1}$ each) as sole sources of carbon and energy (Schwiening, 1999). 17A3 ${ }^{\mathrm{T}}$

Published online ahead of print on 30 July 2004 as DOI 10.1099/ ijs.0.03003-0.

Abbreviations: $\mathrm{PAH}$, polycyclic aromatic hydrocarbon; RISA, rRNA gene internal spacer analysis.

The GenBank/EMBL/DDBJ accession number of the 16S rRNA gene sequence of Mycobacterium pyrenivorans $17 \mathrm{AS}^{\top}$ is $\mathrm{AJ} 431371$. was purified by alternately streaking dilutions of the sample on R2A agar plates and cultivating isolated colonies in mineral medium with PAHs. Purity was confirmed by plating on R2A agar and the recovered single isolate was maintained by repeated transfer to mineral medium with PAH or pyrene $\left(50 \mathrm{mg} \mathrm{l}^{-1}\right)$ and R2A agar plates.

Gram staining, acid-alcohol-fastness, colony morphology, the ability to grow at various temperatures, pigment production and photoreactivity were determined after 2 weeks of growth on R2A agar plates at $28-30{ }^{\circ} \mathrm{C}$ using the methods described by Vincent Lévy-Frébault \& Portaels (1992) and Wayne et al. (1974). The catalase test was performed as described by Kubica \& Pool (1960). Nitrate reductase and Tween 80 hydrolysis were detected as described by Wayne et al. (1974) and by BBL Taxo nitrite test strips. The protocols used to determine growth on xylose, trehalose, mannitol and sorbitol as sole sources of carbon were those of Silcox et al. (1981). The type strains of the closely related species Mycobacterium austroafricanum (DSM $44191^{\mathrm{T}}$ ) (Tsukamura et al., 1983), Mycobacterium aurum $\left(\right.$ DSM $43999^{\mathrm{T}}$ ) (Tsukamura, 1966) and Mycobacterium vaccae (DSM 43292 ${ }^{\mathrm{T}}$ ) (Bönike \& Juhasz, 1964) were tested under identical conditions. Mycobacterium vanbaalenii DSM $7251^{\mathrm{T}}$ (Khan et al., 2002) could not be included in the tests because it was described after performing the experiments. 
The capacity of strain $17 \mathrm{~A}^{\mathrm{T}}$ to degrade different PAHs in liquid batch experiments was tested over a period of 8 weeks by using mineral medium amended with phenanthrene, anthracene, fluoranthene, pyrene and benzo[a]pyrene (20 mg l $\mathrm{l}^{-1}$ each). Remaining PAHs were extracted four times with ethyl acetate by vigorous mixing on a stirring plate. Extracts were analysed by GC, which was performed on a Hewlett Packard 5890 Series II gas chromatograph equipped with a flame-ionization detector. A fused silica column (HP-5, cross-linked 5\% PhMeSilicone, $30 \times 0.25 \mathrm{~mm}, 0.25 \mu \mathrm{m}$ film thickness) with an uncoated deactivated precolumn (Hewlett Packard; Retention Gap, $5 \mathrm{~m} \times 0.32 \mathrm{~mm}$ ) was used. GC conditions were: injector temperature $270{ }^{\circ} \mathrm{C}$; detector temperature $285^{\circ} \mathrm{C}$; the column temperature program was initial temperature $40^{\circ} \mathrm{C}$ for $4 \mathrm{~min}$ followed by a linear gradient of $10^{\circ} \mathrm{C} \mathrm{m^{-1 }}$ to a final temperature of $280^{\circ} \mathrm{C}$, which was maintained for $15 \mathrm{~min}$.

The strain was grown for fatty acid and mycolic acid analysis (HPLC) for 7 days at $35^{\circ} \mathrm{C}$ in Petri dishes on Middlebrook 7H10 medium supplemented with glycerol and OADC (DSMZ medium 645; DSMZ, 2001). Three to four inoculation loops of cell material were scraped from the plates and used directly for the analyses. TLC analyses of mycolic acids were performed with whole-cell methanolysates from freeze-dried cells as described previously (Springer et al., 1995).

Fatty acids were analysed as methyl esters obtained from cells after saponification, methylation and extraction by GC as described previously (Sasser, 1990; Schröder et al., 1997). For mycolic acid analyses by HPLC, the cells were saponified by $\mathrm{KOH}$ and transferred to their bromophenacyl esters as described previously by Butler et al. (1996) and Miller (1997). Mycolic acid bromophenacyl esters were analysed by HPLC operated by the Sherlock System software (MIDI Inc.).

rRNA gene internal spacer analyses (RISA) were carried out with strain $17 \mathrm{~A}^{\mathrm{T}}$ and M. vanbaalenii DSM $7251^{\mathrm{T}}$, M. aurum DSM $43999^{\mathrm{T}}$ and M. austroafricanum DSM $44191^{\mathrm{T}}$ as references using methods described previously (GarciaMartinez et al., 1999; Gürtler \& Stanisich, 1996; Jensen et al., 1993; Ranjard et al., 2000).

Genomic DNA extraction, PCR-mediated amplification of the 16S rRNA gene and purification of PCR products were carried out as described previously (Rainey et al., 1996). The ae2 editor (Maidak et al., 1999) was used to align the almost complete $16 \mathrm{~S}$ rRNA gene sequence of strain $17 \mathrm{~A}^{\mathrm{T}}$ (1451 nt) against the 16S rRNA gene sequences of type strains of the genus Mycobacterium. Phylogenetic analyses (De Soete, 1983; Felsenstein, 1993) followed described methods.

Cells of strain $17 \mathrm{~A} 3^{\mathrm{T}}$ were Gram-positive and acid-fast. The scotochromogenic, rough colonies were yellow, which intensified after exposure to light. In liquid media, the cells clumped together or showed biofilm formation on glass or PAH crystal surfaces. This is probably due to their hydrophobic cell-wall surface. On TSB (trypticase soy broth) agar plates, growth appeared within 7 days at $35^{\circ} \mathrm{C}$. In the semi-quantitative catalase test, the foam height was $>45 \mathrm{~mm}$. The nitrate reduction test showed a weak positive reaction. Strain $17 \mathrm{~A} 3^{\mathrm{T}}$ was not able to hydrolyse Tween 80 within 10 days. Mannitol could be used for growth. Xylose, trehalose and sorbitol could not be assimilated. The results of physiological tests are listed in Table 1.

In mineral salt medium, strain $17 \mathrm{~A} 3^{\mathrm{T}}$ was able to mineralize phenanthrene, fluoranthene and pyrene aerobically. Decreases in anthracene and benzo[a]pyrene concentrations in the PAH-amended culture medium were not detected. In addition, pyrene was used as a sole source of carbon and energy. No loss of degradability was observed after subcultivating the strain on composed media like R2A agar for an extended period.

Separation of whole-organism acid methanolysates by TLC developed in two dimensions produced a multispot pattern composed of alpha-, epoxy and omega-dicarboxy mycolates plus a spot of alcohols (wax-ester mycolates). This pattern was shared by M. aurum, M. austroafricanum, M. vaccae and a few other mycobacteria (Vincent LévyFrébault \& Portaels, 1992; Häggblom et al., 1994; Hinrikson \& Pfyffer, 1994) (data not shown).

Analyses of mycolic acids by HPLC revealed a characteristic UV-HPLC chromatogram of Mycobacterium species that have separated, triple-peak clusters with prominent peaks in the early cluster that emerge prior to $5.0 \mathrm{~min}$. Strain $17 \mathrm{~A} 3^{\mathrm{T}}$ shares this pattern with its relatives M. aurum, $M$. austroafricanum, M. vaccae (Butler \& Guthertz, 2001) and M. vanbaalenii (Khan et al., 2002). Strain $17 \mathrm{~A} 3^{\mathrm{T}}$ can easily

Table 1. Physiological properties of strain $17 A 3^{\top}$ and closely related species

Reference strains: 1, M. austroafricanum DSM 44191 ${ }^{\mathrm{T}} ; 2, M$. aurum DSM $43999^{\mathrm{T}}$; 3, M. vaccae DSM 43292 ${ }^{\mathrm{T}}$. +, Positive; -, negative; \pm , weakly positive; $S$, scotochromogenic; $P$, photozchromogenic. All strains were positive for growth on mannitol and negative for growth on sorbitol.

\begin{tabular}{|lcccc|}
\hline Characteristic & $\mathbf{1 7 A 3}^{\mathbf{T}}$ & $\mathbf{1}$ & $\mathbf{2}$ & $\mathbf{3}$ \\
\hline Formation of pigment & $\mathrm{S}$ & $\mathrm{S}$ & $\mathrm{S}$ & $\mathrm{P}$ \\
Growth at $42^{\circ} \mathrm{C}$ & - & - & - & + \\
Tween 80 hydrolysis & - & $+^{*}$ & + & + \\
Nitrate reduction & \pm & + & - & - \\
Catalase activity (semi-quantitative) & $+\dagger$ & - & + & + \\
Growth on: & & & & \\
$\quad$ Xylose & - & + & + & - \\
Trehalose & - & - & + & - \\
\hline
\end{tabular}

${ }^{\star}$ Hydrolysis within 10 days.

$\dagger$ Foam height $>45 \mathrm{~mm}$. 
be separated from these species by quantitative differences (Table 2).

Analyses of fatty acids by GLC revealed the expected diagnostic pattern for members of the genus Mycobacterium, i.e. straight-chain saturated and unsaturated fatty acids together with a diagnostic amount of tuberculostearic acid (10-methyl-branched octadecanoic acid). The alcohols that were already detected by TLC eluted together with the fatty acids and could be identified as octadecanol (C18:0 alcohol) and eicosanol (C20:0 alcohol) (Table 3). Taking the qualitative and quantitative composition of the

Table 2. Comparison of the mycolic acid pattern (HPLC) of Mycobacterium sp. $17 \mathrm{~A}^{\mathrm{T}}$ with related species

Reference strains: 1, M. aurum DSM $43999^{\mathrm{T}} ; 2$, M. austroafricanum DSM 44191 ${ }^{\mathrm{T}}$; 3, M. vaccae DSM 43292 ${ }^{\mathrm{T}}$; 4, M. vanbaalenii DSM $7251^{\mathrm{T}}$. ECL is equivalent chain-length of mycolic acid in comparison to low (ECL 34.000) and high (ECL 110.000) RIBI molecular internal standards. tr, Traces.

\begin{tabular}{|c|c|c|c|c|c|}
\hline ECL & $17 \mathrm{A3}^{\mathrm{T}}$ & 1 & 2 & 3 & 4 \\
\hline $37 \cdot 497$ & - & - & - & - & $1 \cdot 48$ \\
\hline $40 \cdot 092$ & $0 \cdot 49$ & - & - & - & $0 \cdot 12$ \\
\hline $41 \cdot 831$ & - & - & $0 \cdot 98$ & - & $0 \cdot 41$ \\
\hline $44 \cdot 984$ & $3 \cdot 42$ & - & $10 \cdot 58$ & $1 \cdot 19$ & $8 \cdot 14$ \\
\hline $47 \cdot 035$ & $1 \cdot 65$ & - & - & - & - \\
\hline $48 \cdot 165$ & $16 \cdot 14$ & $23 \cdot 49$ & $27 \cdot 50$ & $4 \cdot 85$ & $16 \cdot 64$ \\
\hline $49 \cdot 515$ & - & $6 \cdot 82$ & - & - & $18 \cdot 24$ \\
\hline $50 \cdot 278$ & $8 \cdot 78$ & - & - & - & - \\
\hline $51 \cdot 145$ & - & $23 \cdot 35$ & - & - & - \\
\hline $51 \cdot 874$ & $13 \cdot 00$ & - & $24 \cdot 52$ & $12 \cdot 18$ & $10 \cdot 35$ \\
\hline $52 \cdot 929$ & $19 \cdot 44$ & - & - & - & - \\
\hline $54 \cdot 957$ & $3 \cdot 41$ & $7 \cdot 03$ & $3 \cdot 90$ & $11 \cdot 73$ & $2 \cdot 44$ \\
\hline $55 \cdot 778$ & $3 \cdot 12$ & - & - & - & - \\
\hline $58 \cdot 528$ & - & - & $0 \cdot 39$ & $4 \cdot 47$ & 0.69 \\
\hline $60 \cdot 703$ & - & - & $1 \cdot 44$ & $2 \cdot 22$ & 0.92 \\
\hline $62 \cdot 063$ & $1 \cdot 25$ & - & - & - & - \\
\hline $64 \cdot 459$ & $4 \cdot 34$ & $4 \cdot 13$ & $9 \cdot 65$ & $5 \cdot 72$ & $8 \cdot 32$ \\
\hline $67 \cdot 378$ & $12 \cdot 49$ & $26 \cdot 01$ & $15 \cdot 14$ & $7 \cdot 47$ & $16 \cdot 54$ \\
\hline $69 \cdot 996$ & - & $2 \cdot 28$ & $2 \cdot 75$ & $2 \cdot 87$ & $3 \cdot 91$ \\
\hline $72 \cdot 841$ & $9 \cdot 30$ & - & - & 0.68 & $2 \cdot 78$ \\
\hline $75 \cdot 080$ & $3 \cdot 18$ & $0 \cdot 78$ & $1 \cdot 09$ & $0 \cdot 80$ & $1 \cdot 39$ \\
\hline $77 \cdot 271$ & - & $0 \cdot 72$ & $0 \cdot 45$ & $0 \cdot 71$ & 0.97 \\
\hline $79 \cdot 157$ & - & $0 \cdot 29$ & - & - & - \\
\hline $81 \cdot 801$ & - & $0 \cdot 43$ & 0.99 & $3 \cdot 58$ & $3 \cdot 41$ \\
\hline $82 \cdot 352$ & $\operatorname{tr}$ & - & - & - & 1.93 \\
\hline $83 \cdot 963$ & - & $1 \cdot 44$ & $0 \cdot 61$ & $9 \cdot 14$ & - \\
\hline $84 \cdot 617$ & $\operatorname{tr}$ & - & - & - & - \\
\hline $86 \cdot 369$ & - & $2 \cdot 51$ & - & $17 \cdot 17$ & $0 \cdot 84$ \\
\hline $86 \cdot 810$ & $\operatorname{tr}$ & - & - & - & - \\
\hline $88 \cdot 477$ & - & $0 \cdot 75$ & - & $11 \cdot 75$ & $0 \cdot 47$ \\
\hline $90 \cdot 346$ & - & - & - & $3 \cdot 20$ & - \\
\hline $92 \cdot 956$ & - & - & - & $0 \cdot 35$ & - \\
\hline
\end{tabular}

Table 3. Comparison of the fatty acid pattern of Mycobacterium sp. $17 \mathrm{~A}^{\mathrm{T}}$ with those of related species

Reference strains: 1, M. aurum DSM 43999 $; 2$, M. austroafricanum DSM 44191 ${ }^{\mathrm{T}}$; 3, M. vaccae DSM $43292^{\mathrm{T}}$; 4, M. vanbaalenii DSM $7251^{\mathrm{T}}$. Abbreviations are exemplified by: cis-7-16:1, cis-7 hexadecenoic acid (palmitoleic acid); 10-methyl-18:0, 10-methyloctadecanoic acid (tuberculostearic acid). Values are percentages of total fatty acids. Major fatty acids ( $>15 \%)$ are in bold.

\begin{tabular}{|lccccc|}
\hline Fatty acid & $\mathbf{1 7 A 3}^{\mathbf{T}}$ & $\mathbf{1}$ & $\mathbf{2}$ & $\mathbf{3}$ & $\mathbf{4}$ \\
\hline $10: 0$ & - & - & - & - & $0 \cdot 05$ \\
$12: 0$ & - & - & - & $0 \cdot 40$ & $0 \cdot 09$ \\
$14: 0$ & $2 \cdot 93$ & $3 \cdot 43$ & $2 \cdot 55$ & $1 \cdot 67$ & $2 \cdot 71$ \\
$15: 0$ & $0 \cdot 23$ & $0 \cdot 56$ & $0 \cdot 33$ & $0 \cdot 78$ & $0 \cdot 80$ \\
cis-7-16:1 & $2 \cdot 41$ & $0 \cdot 79$ & $0 \cdot 89$ & - & $0 \cdot 95$ \\
cis-9-16:1 & $0 \cdot 66$ & $0 \cdot 94$ & $10 \cdot 65$ & $5 \cdot 29$ & - \\
cis-10-16:1 & $7 \cdot 93$ & $6 \cdot 85$ & - & $6 \cdot 35$ & $10 \cdot 34$ \\
$16: 0$ & $\mathbf{2 5} \cdot \mathbf{2 0}$ & $\mathbf{2 3 \cdot 3 5}$ & $\mathbf{2 7 \cdot 5 9}$ & $\mathbf{2 3} \cdot \mathbf{4 9}$ & $\mathbf{2 9} \cdot 11$ \\
8 -methyl-16:0 & $0 \cdot 15$ & - & - & $1 \cdot 15$ & $0 \cdot 79$ \\
$10-$ methyl-16:0 & - & - & $0 \cdot 42$ & - & - \\
$17: 0$ & $0 \cdot 22$ & $0 \cdot 35$ & $0 \cdot 25$ & $0 \cdot 76$ & $0 \cdot 57$ \\
$18: 2$ & $0 \cdot 15$ & - & $0 \cdot 18$ & $1 \cdot 37$ & $0 \cdot 23$ \\
cis-9-18:1 & $\mathbf{3 0 \cdot 4 3}$ & $\mathbf{1 9 \cdot 7 4}$ & $8 \cdot 85$ & $\mathbf{2 8 \cdot 3 1}$ & $10 \cdot 52$ \\
cis-11-18:1 & $0 \cdot 22$ & - & $0 \cdot 37$ & $1 \cdot 48$ & $0 \cdot 48$ \\
$18: 0$ & $3 \cdot 20$ & $1 \cdot 59$ & $2 \cdot 75$ & $1 \cdot 74$ & $1 \cdot 81$ \\
10 -methyl-18:0 & $7 \cdot 47$ & $12 \cdot 62$ & $14 \cdot 24$ & $10 \cdot 35$ & $12 \cdot 30$ \\
$20: 0$ & $0 \cdot 62$ & - & $0 \cdot 29$ & - & $0 \cdot 19$ \\
$18: 0$ alcohol & $12 \cdot 54$ & $12 \cdot 59$ & $\mathbf{1 5 \cdot 6 6}$ & $12 \cdot 74$ & $\mathbf{1 6} \cdot 31$ \\
$20: 0$ alcohol & $5 \cdot 64$ & $\mathbf{1 5 \cdot 1 9}$ & $\mathbf{1 5 \cdot 0 1}$ & $4 \cdot 12$ & $12 \cdot 78$ \\
& & & & & \\
\hline
\end{tabular}

fatty acids into consideration, this pattern resembles those of $M$. aurum/M. austroafricanum. The fatty acid pattern of strain $17 \mathrm{~A} 3^{\mathrm{T}}$ was identified by the Microbial Identification System (MIDI Inc.) as M. aurum but with only a low correlation.

In order to characterize strain $17 \mathrm{~A} 3^{\mathrm{T}}$ further and to compare it with closely related strains on the DNA level, we conducted RISA analysis. Spacer regions between the $16 \mathrm{~S}$ and $23 \mathrm{~S}$ rRNA genes show a certain degree of length variation (Gürtler \& Stanisich, 1996; Garcia-Martinez et al., 1999). These spacers can be easily amplified by means of universal PCR primers with similarity to the conserved flanking sequences. RISA can be used for both molecular characterization of a bacterial species and ecological studies of the diversity of prokaryotic communities (e.g. Ranjard et al., 2000; Sigler et al., 2002). Length polymorphisms occur to a minor degree within a species. The diversity of spacer length is greater if different species or genera are compared, although distantly related species may produce the same RISA pattern (Sonderkamp et al., 2001). Fig. 1 shows the patterns of the intergenic rRNA gene spacer amplificates from strain $17 \mathrm{~A} 3^{\mathrm{T}}$, M. vanbaalenii DSM $7251^{\mathrm{T}}$, M. aurum DSM $43999^{\mathrm{T}}$ and M. austroafricanum DSM $44191^{\mathrm{T}}$.

With intrageneric 16S rRNA gene sequence similarities 


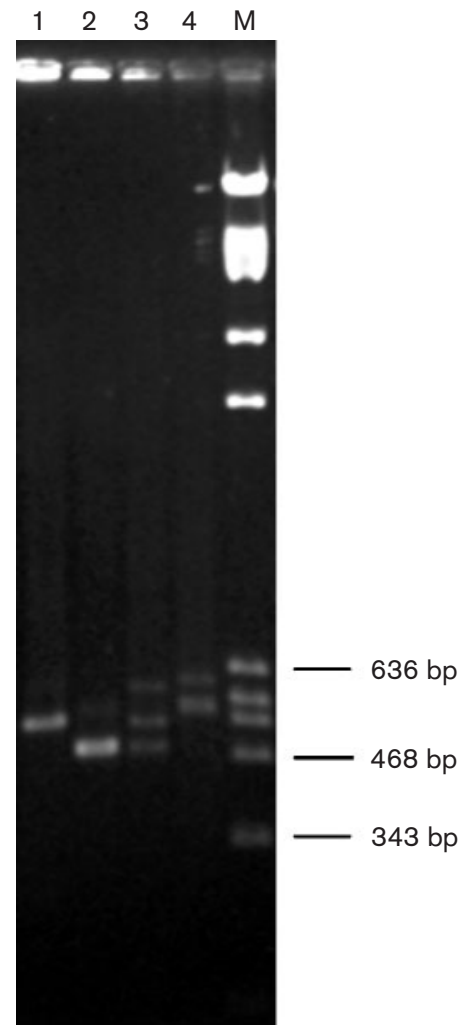

Fig. 1. RISA patterns of Mycobacterium species. Lanes: 1, Mycobacterium sp. $17 \mathrm{A3}^{\top} ; 2$, M. vanbaalenii DSM $7251^{\top}$; 3, M. austroafricanum DSM $44191^{\top} ; 4$, M. aurum DSM 43999'; M, Pvull-restricted $\lambda$ DNA.

ranging between 94.6 and $98.6 \%$, strain $17 \mathrm{~A} 3^{\mathrm{T}}$ is a member of the genus Mycobacterium, closely related to M. austroafricanum DSM $44191^{\mathrm{T}}(98 \cdot 6 \%)$, M. vanbaalenii DSM $7251^{\mathrm{T}}$ (98.5\%), M. aurum DSM $43999^{\mathrm{T}}(98 \cdot 5 \%)$ and M. vaccae DSM $43292^{\mathrm{T}}(97 \cdot 8 \%)$. Both distance-matrix and maximum-likelihood analysis gave consistent results in that strain $17 \mathrm{~A} 3^{\mathrm{T}}$ clustered adjacent to type strains of $M$. vanbaalenii, $M$. austroafricanum, $M$. vaccae and $M$. aurum, though the bootstrap value for the branching point of this lineage was only $58 \%$ (Fig. 2; distance-matrix tree). The presence of clear differences in genomic (RISA, 16S rRNA gene sequence), chemotaxonomic (mycolic acids, fatty acids) and physiological properties in the five members of the $M$. aurum sublineage of the genus Mycobacterium and the finding that $16 \mathrm{~S}$ rRNA gene similarity values determined for these five type strains are similar or even lower than those found for several other pairs of type strains of Mycobacterium species (e.g. M. aurum DSM $43999^{\mathrm{T}}$ and M. vanbaalenii DSM $7251^{\mathrm{T}}, 98 \cdot 7 \%$; M. vaccae DSM $43292^{\mathrm{T}}$ and M. vanbaalenii DSM $7251^{\mathrm{T}}, 99 \cdot 3 \%$; or Mycobacterium fortuitum DSM $46621^{\mathrm{T}}$ and Mycobacterium senegalense DSM $43656^{\mathrm{T}}, 99 \cdot 4 \%$ ) justifies the description of a novel species for strain $17 \mathrm{~A} 3^{\mathrm{T}}$, for which the name Mycobacterium pyrenivorans sp. nov. is proposed.

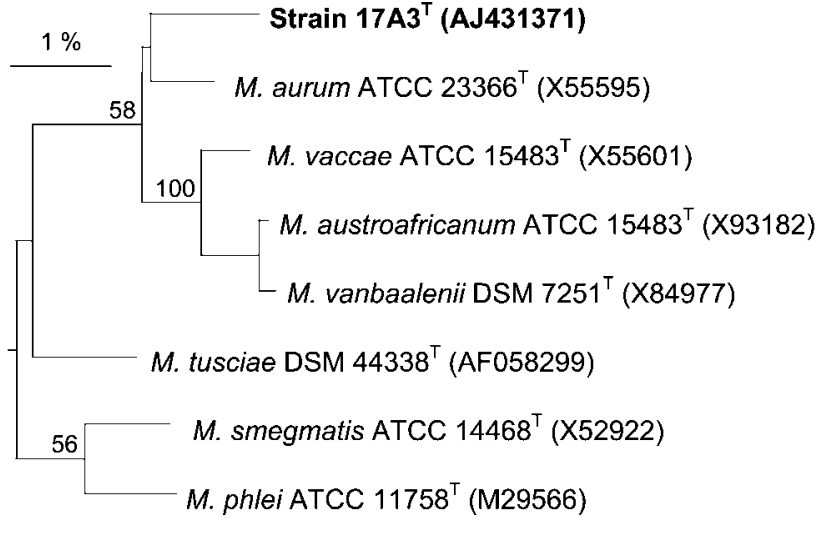

Fig. 2. Phylogenetic relatedness of the pyrene-metabolizing strain $17 \mathrm{A3}^{\top}$ among closely related type strains of Mycobacterium species, based upon 16S rRNA gene sequence comparison. More distantly related type strains of the genus served as the root. The dendrogram was generated by distance matrix analysis (De Soete, 1983). Numbers within the dendrogram indicate the percentages of occurrence of the branching order in 100 bootstrapped trees (only values of $50 \%$ and above are shown). The scale bar represents 1 nucleotide substitution per 100 nucleotides.

\section{Description of Mycobacterium pyrenivorans sp. nov.}

Mycobacterium pyrenivorans (py.re.ni.vo'rans. N.L. n. pyrenum pyrene; L. v. vorare to devour; L. part. adj. vorans devouring, digesting; N.L. part. adj. pyrenivorans digesting pyrene).

Cells are strictly aerobic, Gram-positive, acid-fast rods. The rough colonies show a yellow colour, which intensifies after exposure to light. In liquid media, the cells clump together or show biofilm formation on glass. On TSA, growth appears within 7 days at $35^{\circ} \mathrm{C}$. Cells grow well between 24 and $37^{\circ} \mathrm{C}$ but not at $42^{\circ} \mathrm{C}$. Classified as a scotochromogenic, rapidly growing mycobacterium. Catalase-positive. Nitrate reduction test shows a weak reaction. Does not hydrolyse Tween 80 within 10 days. Mineralizes phenanthrene, fluoranthene and pyrene but not anthracene or benzo[a]pyrene. Can use mannitol as a sole source of carbon but can not grow on xylose, trehalose or sorbitol. The fatty acid pattern from whole-cell methanolysates is composed of tetradecanoic acid (3\%), cis-7-hexadecenoic acid (3\%), palmitic acid (25\%), oleic acid $(31 \%)$, stearic acid (3\%), tuberculostearic acid $(8 \%)$ and eicosanoic acid (1\%). Significant amounts of alcohols 2-octadecanol (13\%) and eicosanol (6\%) are also present. TLC of mycolic acid methanolysates reveals alphamycolates, epoxy-mycolates and omega-carboxymycolates plus 2-eicosanol (wax-ester mycolates). The mycolic acid HPLC elution profile is unique and can be used for differentiation from the closely related species $M$. aurum, 
M. austroafricanum, $M$. vaccae and M. vanbaalenii and all other mycobacteria.

The type strain, $17 \mathrm{~A} 3^{\mathrm{T}}\left(=\mathrm{DSM} 44605^{\mathrm{T}}=\mathrm{NRRL} \mathrm{B}-24244^{\mathrm{T}}\right)$, was isolated from soil of a former coking plant at ÜbachPalenberg, Germany.

\section{Acknowledgements}

We would like to thank Gabriele Pötter, Jolantha Swiderski, Ina Kramer and Arnoldine Carlier for expert technical assistance during this study.

\section{References}

Bell, K., Philip, J. C., Aw, D. W. J. \& Christofi, N. (1998). The genus Rhodococcus. J Appl Microbiol 85, 195-210.

Bönike, R. \& Juhasz, S. E. (1964). Beschreibung der neuen spezies Mycobacterium vaccae n. $\mathrm{sp}$. Zentralbl Bakteriol Parasitenkd Infekt Hyg Abt I 192, 133-135.

Butler, W. R. \& Guthertz, L. S. (2001). Mycolic acid analysis by high-performance liquid chromatography for identification of Mycobacterium species. Clin Microbiol Rev 14, 704-726.

Butler, W. R., Floyd, M. M., Silcox, M. S. \& 9 other authors (1996). Standardized Method for HPLC Identification of Mycobacteria. Atlanta, GA: CDC, US Department of Health and Human Services.

De Soete, G. (1983). A least square algorithm for fitting additive trees to proximity data. Psychometrika 48, 621-626.

DSMZ (2001). Catalogue of Strains, 7th edn. Braunschweig: DSMZ.

Felsenstein, J. (1993). PHYLIP (phylogenetic inference package) version 3.5c. Distributed by the author. Department of Genetics, University of Washington, Seattle, USA.

Garcia-Martinez, J., Acinas, S. G., Anton, A. I. \& Rodriguez-Valera, F. (1999). Use of the 16S-23S ribosomal genes spacer region in studies of prokaryotic diversity. J Microbiol Methods 36, 55-64.

Gürtler, V. \& Stanisich, V. A. (1996). New approaches to typing and identification of bacteria using the 16S-23S rDNA spacer region. Microbiology 142, 2-16.

Häggblom, M. M., Nohynek, L. J., Palleroni, N. J., Kronqvist, K., Nurmiaho-Lassila, E.-L., Salkinoja-Salonen, M. S., Klatte, S. \& Kroppenstedt, R. M. (1994). Transfer of polychlorophenol-degrading Rhodococcus chlorophenolicus (Apajalathi et al. 1986) to the genus Mycobacterium as Mycobacterium chlorophenolicum comb. nov. Int J Syst Bacteriol 44, 485-493.

Hinrikson, H. P. \& Pfyffer, G. E. (1994). Mycobacterial mycolic acids. Med Microbiol Lett 3, 49-57, 97-106.

Jensen, M. A., Webster, J. A. \& Straus, N. (1993). Rapid identification of bacteria on the basis of polymerase chain reactionamplified ribosomal DNA spacer polymorphisms. Appl Environ Microbiol 59, 945-952.

Khan, A. A., Kim, S.-J., Paine, D. D. \& Cerniglia, C. E. (2002). Classification of a polycyclic aromatic hydrocarbon-metabolizing bacterium, Mycobacterium sp. strain PYR-1, as Mycobacterium vanbaalenii sp. nov. Int J Syst Evol Microbiol 52, 1997-2002.

Kubica, G. P. \& Pool, G. L. (1960). Studies on the catalase activity of acid-fast bacilli. I. An attempt to subgroup these organisms on the basis of their catalase activities at different temperatures and $\mathrm{pH}$. Am Rev Respir Dis 81, 387-391.
Maidak, B. L., Cole, J. R., Parker, C. T., Jr \& 11 other authors (1999). A new version of the RDP (Ribosomal Database Project). Nucleic Acids Res 27, 171-173.

Miller, J. L. (1997). Sherlock Mycobacteria Identification by High Performance Liquid Chromatography. A Training Manual. Newark, DE: MIDI Inc.

Rainey, F. A., Ward-Rainey, N., Kroppenstedt, R. M. \& Stackebrandt, E. (1996). The genus Nocardiopsis represents a phylogenetically coherent taxon and a distinct actinomycete lineage: proposal of Nocardiopsaceae fam. nov. Int J Syst Bacteriol 46, 1088-1092.

Ranjard, L., Poly, F., Combrisson, J., Richaume, A., Gourbiere, F., Thioulouse, J. \& Nazaret, S. (2000). Heterogeneous cell density and genetic structure of bacterial pools associated with various soil microenvironments as determined by enumeration and DNA fingerprinting approach (RISA). Microb Ecol 39, 263-272.

Sasser, M. (1990). Identification of bacteria by gas chromatography of cellular fatty acids. MIDI Technical Note 101. Newark, DE: MIDI Inc.

Schröder, K.-H., Naumann, L., Kroppenstedt, R. M. \& Reischl, U. (1997). Mycobacterium hassiacum sp. nov., a new rapidly growing thermophilic mycobacterium. Int J Syst Bacteriol 47, 86-91.

Schwiening, S. (1999). Mikrobieller Abbau von ${ }^{14} C$-markiertem Benzo[a]pyren durch PAK-adaptierte Bakterienmischkulturen. $\mathrm{PhD}$ thesis, Aachen University. Aachen: Shaker Verlag.

Sigler, W. V., Crivii, S. \& Zeyer, J. (2002). Bacterial succession in glacial forefield soils characterized by community structure, activity, and opportunistic growth dynamics. Microb Ecol 44, 306-316.

Silcox, V. A., Good, R. C. \& Floyd, M. M. (1981). Identification of clinically significant Mycobacterium fortuitum complex isolates. J Clin Microbiol 14, 686-691.

Sonderkamp, S., Vomberg, A., Schmitz, C., Faßbender, U. \& Klinner, U. (2001). Interactions between bacterial populations during degradation of a lubricant base oil. FEMS Microbiol Ecol 38, 97-104.

Springer, B., Tortoli, E., Richter, I. \& 7 other authors (1995). Mycobacterium conspicuum sp. nov., a new species isolated from patients with disseminated infections. J Clin Microbiol 33, 2805-2811.

Stackebrandt, E., Rainey, F. \& Ward-Rainey, N. (1997). Proposal for a new hierarchic classification system, Actinobacteria classis nov. Int J Syst Bacteriol 47, 479-491.

Tsukamura, M. (1966). Adansonian classification of mycobacteria. J Gen Microbiol 45, 253-273.

Tsukamura, M., van der Meulen, H. J. \& Grabow, W. O. K. (1983). Numerical taxonomy of rapidly growing, scotochromogenic mycobacteria of the Mycobacterium parafortuitum complex: Mycobacterium austroafricanum sp. nov. and Mycobacterium diernhoferi sp. nov., nom rev. Int J Syst Bacteriol 33, 460-469.

Vincent Lévy-Frébault, V. \& Portaels, F. (1992). Proposed minimal standards for the genus Mycobacterium and for description of new slowly growing Mycobacterium species. Int J Syst Bacteriol 42, 315-323.

Wayne, L. G., Engbaek, H. C., Engel, H. W. B. \& 17 other authors (1974). Highly reproducible techniques for use in systematic bacteriology in the genus Mycobacterium: tests for pigment, urease, resistance to sodium chloride, hydrolysis of Tween 80 , and $\beta$-galactosidase. Int J Syst Bacteriol 24, 412-419.

Williumsen, P. A. \& Karlson, U. (1997). Screening of bacteria, isolated from $\mathrm{PAH}$-contaminated soils, for production of biosurfactants and bioemulsifiers. Biodegradation 7, 415-423. 